\title{
Design and Analysis of Compact Dual Band U-Slot Microstrip Patch Antenna with Defected Ground Structure for Wireless Application
}

\author{
S LeoPauline ${ }^{1 *}$, T R Ganesh Babu ${ }^{2}$ \\ ${ }^{1}$ Research Scholar, Anna University, Chennai, India. \\ ${ }^{2}$ Professor in Department of Electronics and Communication Engineering, Muthyammal Engineering College, Rasipuram, India. \\ *Corresponding author E-mail: sleopauline15@gmail.com
}

\begin{abstract}
This paper explore about the micro strip patch antenna design with a defected ground structure (DGS) for dual band operation. The intend of this paper is to design an micro strip antenna, under the frequency at $2.4 \mathrm{GHz}$ and $5.2 \mathrm{GHz}$ that can be utilized for BLUETOOTH and WLAN applications. The feeding technique used here is coaxial feed technique. The above said double band property can be established by etching U-slot in the ground plane. Being periodic structure slot is selected and it is imposed on ground plane. The periodic structures naturally modify the method of propagation of the electromagnetic signal passing on to the antenna. Essentially its core is to vary the parasitic capacitance and inductance of the material through which the substrate is made. This may moreover leads to the reduction in size and progress the performance of the antenna. Micro strip patch antennae are favored due to the fact that these are small in size, inexpensive, consume low power and easy to fabricate and also be designed to meet wide band application requirements.
\end{abstract}

Keywords: Microstrip Patch Antenna (MPA), Defected Ground Structure (DGS) and Wideband application.

\section{Introduction}

In general wireless communication is based on radio waves, are the ways to transmit information over the distance not including any physical medium such as wires or connecting cables. Communication can be established between people every day by means of pager, cellular, telephones, laptops, a variety of personal digital assistants and other wireless communication product. Hence for the purpose of telecommunication, is assisted as transmission of signals over a distance.

In early time before the usage of radio waves the communication may happened by the use of smoke signals (created using fire), drums (voice signals), semaphore (an apparatus for conveying message by means of visual signals), flags or heliograph (a device for signaling by means of a movable mirror that reflects beam of light) especially during the time of disaster.

In modern times, an antenna is designed to transmit or receive radio waves. It is used to couple energy from a guiding structure such as transmission line or waveguide into free space and vice versa. Thus, without any prevailing structures the information can be transferred between different locations. Besides, antennae are essential in such situations where it is impractical and uneconomical to offer guiding structures between the source and the recipient.

MPA is one of the types of an antenna that has a two sided dielectric substrate patch, radiating patch on one side of a dielectric substrate and a ground plane on the other. For a superior antenna performance, a thick dielectric substrate having allowed dielectric constant is desirable as it provides better efficiency, larger band- width and better radiation. Nevertheless, such a bulky dielectric substrate leads to a enhanced antenna size. Designing a smaller sized MPA, privileged dielectric constants must be used but it turn, it results to narrower bandwidth and less efficiency, consequently there has to be reached a negotiation between antenna dimensions and performance. Generally the micro strip patches are made of guiding material and can acquire any possible shape as shown in Figure 1.

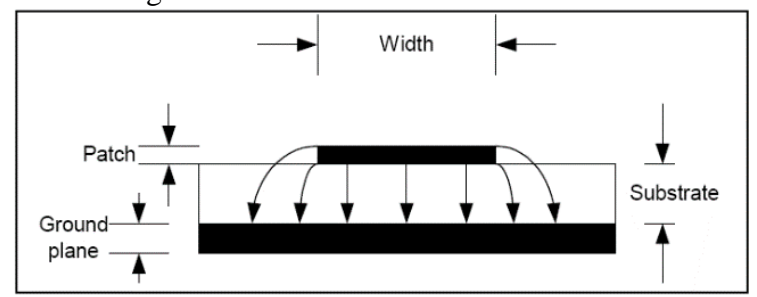

Fig. 1: Cross-Sectional View of a MPA

\section{Feeding Techniques}

The most common techniques used in the design of MPAs is Coaxial probe feed technique. As seen in Figure 2, the external or the outer conductor of the coaxial cable is attached to the ground plane and the inner conductor of the coaxial connector is made extended all the way through the dielectric and is soldered to that of the radiating patch. Unlike other techniques, the coaxial probe feed has the flexibility of insertion the feed so as to get perfect input impedance matching which may helps to avoid return loss. Also provides an easy approach for the fabrication. 


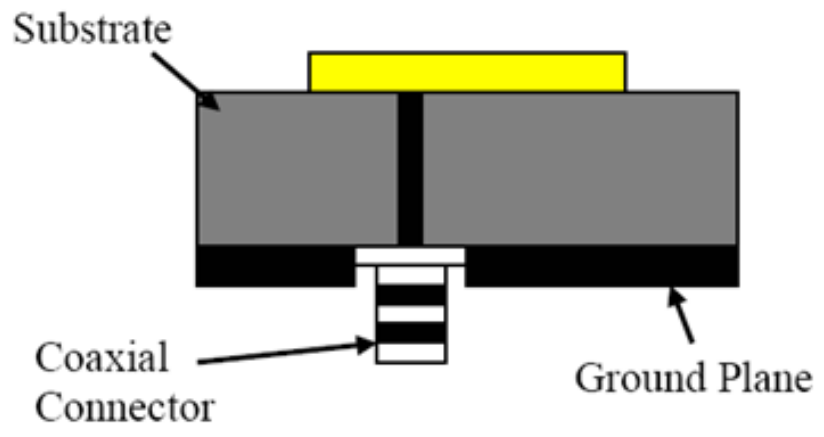

Fig. 2: Coaxial Probe Feed Technique

By calculating the feed line length and the width -to - linearization perfect matching can be achieved which avoids the return loss The foremost drawback of this scheme is that during fabrication process, in view of the fact that two dielectric layers which necessitate appropriate alignment, furthermore there is an overall increase in the thickness of the antenna.

\section{Defected Ground Structure (Dgs)}

DGS can be obtained by establishing defected shape on a ground plane; this will perturb the shielded current distribution which depends on the shape of defect. The interruption at the shielded current sharing will manipulate the input impedance and the current flow to the antenna. The above said defected structure is a distinctive technique to decrease the size of an antenna, which is considered to be preliminary requirement in antenna design.

The surface excitation occurs due to the presence of substrate leads to losses that may reduce the antenna efficiency, gain and bandwidth. As surface waves occur, it can take out total available power for radiation to space wave. This surface excitation can be decreased by the use of defected ground structure, which is a slot or resonant gap in the ground metal, positioned beneath a transmission line associated for coupling.

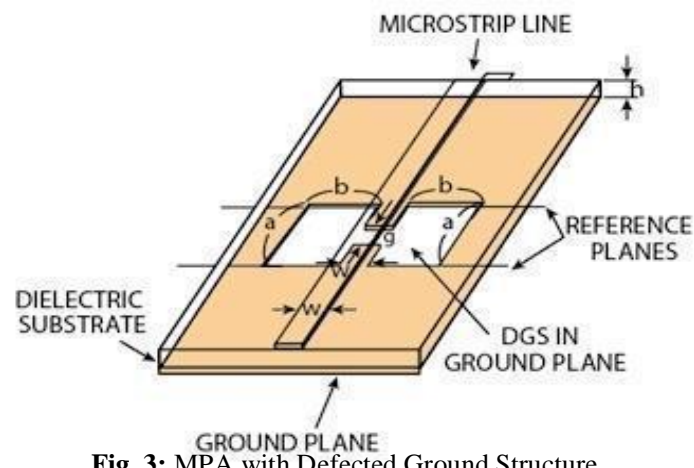

Several resonant structures may be used to achieve better coupling that may reduce standing waves.

\section{Design Parameters}

The following are the design steps,

Step 1:

The width of patch is designed as,

$$
W=\frac{C_{0}}{2 f_{r}} \sqrt{\frac{2}{\varepsilon_{r}+1}}
$$

Where,

$$
\begin{aligned}
& W=\text { Width of the patch } \\
& C_{0}=\text { Speed of light } \\
& \varepsilon_{r}=\text { value of the dielectric substrate }
\end{aligned}
$$

Here the patch width are premeditated as

$\mathrm{W} 1=1 \mathrm{~mm}, \mathrm{~W} 2=1.2 \mathrm{~mm}, \mathrm{~W} 3=0.6 \mathrm{~mm}$.

Step 2:

Electrically the size of an antenna can be increases by increase in length $(\Delta \mathrm{L})$ but by increasing the length may lead to fringing effect. Consequently, the increase in length $(\Delta \mathrm{L})$ of the patch is to be calculated by the following equation

$$
\begin{aligned}
& \varepsilon_{\text {reff }}=\frac{\varepsilon_{r}+1}{2}+\frac{\varepsilon_{r}-1}{2}\left[1+12 \frac{h}{W}\right]^{-1 / 2}, W / h>1 \\
& \frac{\Delta L}{h}=0.412 \frac{\left(\varepsilon_{\text {reff }}+0.3\right)\left(\frac{W}{h}+0.264\right)}{\left(\varepsilon_{\text {reff }}-0.258\right)\left(\frac{W}{h}+0.8\right)} \\
& L=\frac{C_{0}}{2 f_{r} \sqrt{\varepsilon_{\text {reff }}}}-2 \Delta L
\end{aligned}
$$

Here the calculated lengths are $\mathrm{L} 1=6 \mathrm{~mm}, \mathrm{~L} 2=5.9 \mathrm{~mm}, \mathrm{~L} 3=2.6 \mathrm{~mm}$.

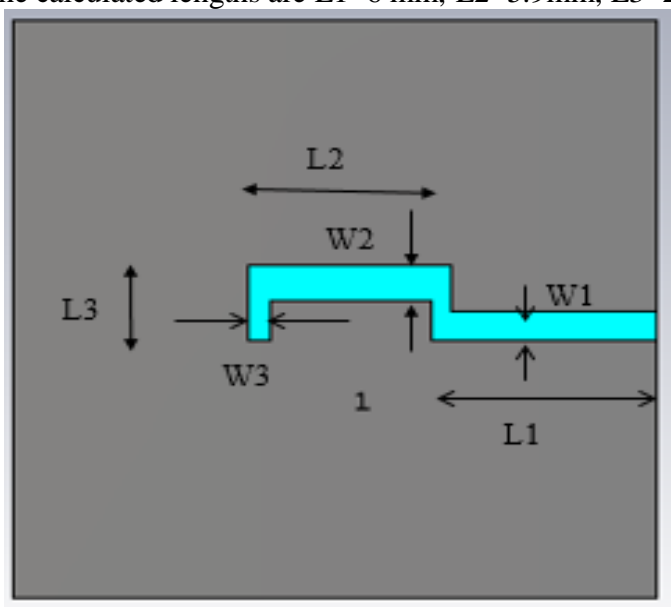

Fig. 4: Design of U slot antenna

By considering all parameters the design is stimulated by using CST Simulation Software.

\section{Experimental Results}

The antenna has been simulated with full wave EM simulator Microwave Studio of CST Studio Suite software package .CST uses the FEM technique for the calculation of different parameters Here two important parameters such as return loss and radiation pattern of antenna are calculated.

i) Return Loss: Despite the fact that designing and fabricating an antenna, a unique concern must be taken for the impedance matching. The reason behind is that the antenna elements load signals to the transmission line. If the input impedance of the antenna is not matched to the impedance of the transmission line said to be improper matching then a portion of the transmitted wave is reflected back as return loss and therefore, affects the antenna efficiency. 


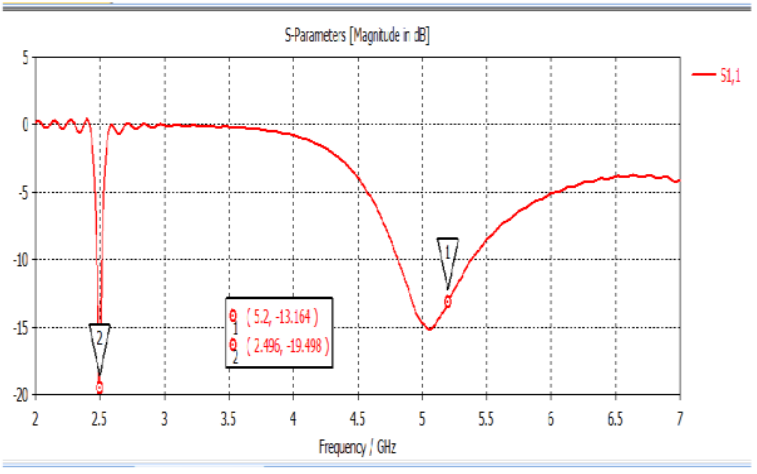

Fig. 5: The return loss

ii) Radiation Loss: The radiation pattern of antenna is the graphical representation the radiating/receiving properties of the antenna as a function of space coordinates in the far-field region. The obtained radiation results are as shown,
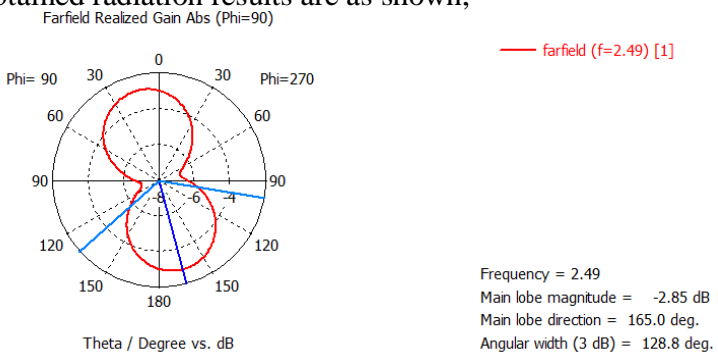

Fig. 6: MPA radiation pattern at $2.4 \mathrm{GHz}$

Farfield Realized Gain Abs (Phi=90)

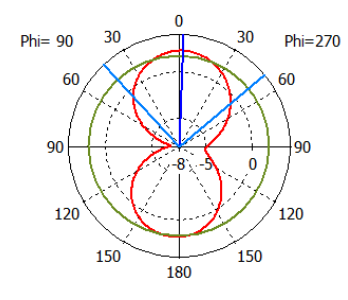

Theta / Degree vs. dB

Fig. 7: MPA radiation pattern at $5.2 \mathrm{GHz}$

\section{Frequency $=5.2$}

Main lobe magnitude $=2.25 \mathrm{~dB}$ Main lobe direction $=2.0 \mathrm{deg}$. Angular width $(3 \mathrm{~dB})=92.8 \mathrm{deg}$.

\section{Conclusion}

A micro strip patch antenna having U-slot with DGS has been designed, with a complete analysis on return loss and radiation pattern parameters. With the frequency of the proposed system are $2.49 \mathrm{GHz}$ and $5.2 \mathrm{GHz}$ which is appropriate for BLUETOOTH and Wireless LAN application. By the use DGS structure the size and return loss can be reduced and hence antenna provides high gain and bandwidth.

\section{References}

[1] S. H. S. Esfahan, A. Tawakoni, and P. Dehkhoda (2011), "A Compact Single-Layer Dual-Band Microstrip Antenna for Satellite Applications," IEEE Antennas and Wireless Propagation Letters, vol. 10, pp. 931-934.

[2] W.C. Liu and W.R. Chen (2004), "CPW-fed compact meandered patch antenna for dual-band operation," Electronics Letters, vol. 40, issue 18, pp. 1094-1095.

[3] L. Liu, Y.F. Weng, S. W. Cheung, T. I. Yuk, and L. J. Foged (2011), "Modeling of cable for measurements of small monopole antennas," IEEE Loughborough Antennas and Propagation Conference (LAPC), pp. 1-4.

[4] G. Liu, D. Wang, F. Jin and S. Chang (2011),“Compact Broad Dual-Band Antenna Using A Shorted Patch with A Thick Air Substrate for Wireless Body Area Network Application,” International Symposium on Microwave, Antenna, Propagation and EMC Technologies for Wireless Communications (MAPE), pp. 18-21.

[5] S. Nagar, U. Nagar and R. S. Meena (2013),"CPW - Fed dual-band patch antenna for mobile applications," 5th International Confer- ence on Computational Intelligence and Communication Networks (CICN), pp. 1-5.

[6] Prabhakar H.V., U.K. Kummuri, R.M. Yadahalli and V. Munnappa (2007), "Effect of various meandering slots in rectangular microstrip antenna ground plane for compact broadband operation," Electronics Letters, vol. 43, issue 16, pp. 848-850.

[7] A. Saghir, S. M. Abbas, M. U. Afzal, T. Tauqeer and M. H. Tariq (2013), "Compact Dual-band Microstrip Antenna Design Using Slits, " International Conference on computer, control and communication (IC4), pp. 1-4. 